\title{
Tuning Solution Chemistry for Morphology Control of Lithium- Ion Battery Precursor Particles
}

\author{
J. Pierce Robinson and Gary M. Koenig Jr.* \\ Department of Chemical Engineering \\ University of Virginia, 102 Engineers Way \\ Charlottesville, VA 22904-4741 \\ *To whom correspondence should be addressed. \\ Tel: (434) 982-2714. \\ Fax: (434) 982-2658. \\ E-mail: gary.koenig@ virginia.edu
}




\section{Introduction}

Lithium-ion batteries have become the dominant technology for consumer electronics applications and are increasingly being developed for larger-scale applications such as electric vehicle batteries and stationary energy storage. ${ }^{1}$ While historically battery progress has largely been tracked by adoption of chemistries and materials structures with higher energy densities, ${ }^{2,3,4}$ another important factor in battery performance is the morphology of the electrochemically active particles within the battery electrode as well as their organization and distribution within the composite structure. For example, the battery materials literature is full of the synthesis and characterization of materials with a wide variety of particle shapes and sizes, including rods, ${ }^{5} 6$ cubes, ${ }^{7}$ spheres, ${ }^{89}$ urchins, ${ }^{10}$ plates, ${ }^{11}$ and many others. ${ }^{12,13,14,15}$ In some cases, the morphology serves to provide preferential diffusion paths for lithium or conduction paths for electrons that improve rate capability or energy density of the battery material. ${ }^{11}$ In other reports, the morphology is taken advantage of to organize the overall electrode structure to accommodate improvements in lithium-ion diffusion in and out of the electrode as a whole. ${ }^{16}$ One of the key factors in being able to take advantage of active particle morphology-dependent improvements in battery electrode performance is that the electrode particle morphology must be wellcontrolled. ${ }^{17}$ Thus, underlying mechanisms that result in the final particle morphology with regards to size, shape, porosity, surface roughness, and polydispersity are important to engineering particles for battery electrodes. In addition, tunability of one or more of these morphology metrics would also be desirable. The study described herein focuses on efforts to control particle morphology in a battery electrode precursor particle system. 
The chemistry employed to synthesize precursor particles in this study was coprecipitation of $\mathrm{Mn}^{2+}$ with carbonate salts to form $\mathrm{MnCO}_{3}$. Coprecipitation was chosen as a method because it is highly tunable and easily scalable for particle synthesis, $, 18,19202122$ and $\mathrm{MnCO}_{3}$ was chosen as a target precursor chemistry because it can be calcined with a lithium source to form the final battery material $\mathrm{LiMn}_{2} \mathrm{O}_{4} \cdot{ }^{23}$ Given the relatively lower complexity of only having one transition metal involved in the coprecipitation synthesis and the availability of data on $\mathrm{LiMn}_{2} \mathrm{O}_{4}$ in the battery literature, ${ }^{24,25}{ }^{26}{ }^{27} \mathrm{MnCO}_{3}$ serves as a model system for precursor morphology tunability. A number of reports have previously been published in the literature on synthesis of transition metal carbonates, including $\mathrm{MnCO}_{3}$, and a variety of particle morphologies that may be achieved. ${ }^{13,28,29,30,31}$ Notably, the most commonly reported morphology for transition metal carbonates used for battery material templates is approximately spherical and has relatively high polydispersity. ${ }^{13,32,33}$ The extent of the tunability of the morphologies and polydispersity of transition metal carbonate template particles, however, is currently unknown. The ability to be predictive in the resultant morphology of these particles would in principle enable detailed studies of the influence of particle morphologies on lithium-ion battery performance.

In general, the morphology of particles generated from coprecipitation reactions can be influenced by a variety of factors, including reagent concentrations, nucleation and growth rates, ripening, collisions with reactor walls and other particles, temperature, and chemical modifiers including chelating agents. ${ }^{18,34,19}$ Due to the high level of complexity for consideration of all of these factors, we have focused our initial study on the influence of solution chemistry on particle morphology. In this paper, we will demonstrate a variety of particle morphologies that are accessible via relatively modest changes in coprecipitation solution chemistry. These morphologies are likely not driven by ripening processes that have been demonstrated to 
influence morphologies for other coprecipitation processes for battery particles previously reported in the literature for hydroxide synthesis ${ }^{34}$. The conversion of our precursor particles to lithiated battery electrode active materials was also performed to demonstrate that the tunable morphologies can be retained in the resulting final electrode materials. While our solution chemistry approach is an initial report of understanding the morphology tunability of this battery precursor system, we speculate a wide design space of size, shape, and surface roughness control will be accessible via detailed study of this synthesis platform.

\section{Experimental}

\section{Preparation of $\mathrm{MnCO}_{3}$ and $\mathrm{LiMn}_{2} \mathrm{O}_{4}$ Particles}

$\mathrm{MnCO}_{3}$ particles were prepared as follows: $1200 \mathrm{~mL}$ of 1.5-240 $\mathrm{mM} \mathrm{NH}_{4} \mathrm{HCO}_{3}$ (Fischer) in deionized (DI) water was poured all at once into $1200 \mathrm{~mL}$ of $1.5-12 \mathrm{mM} \mathrm{MnSO} \cdot \mathrm{H}_{2} \mathrm{O}$ (Fischer) in DI water solution in a $4 \mathrm{~L}$ beaker. Solutions were preheated to $50{ }^{\circ} \mathrm{C}$ prior to mixing and the temperature was maintained at $50{ }^{\circ} \mathrm{C}$ for the duration of the synthesis. The solution was stirred gently with an impeller at $500 \mathrm{rpm}$ to prevent particle settling in solution and $\mathrm{MnCO}_{3}$ particles were precipitated for $0.5 \mathrm{~h}$. All syntheses were done at a pH of 7.5 . Vacuum filtration was used to collect the particles, and the particle cake was rinsed with $2 \mathrm{~L}$ DI water before being vacuum dried at $80{ }^{\circ} \mathrm{C}$ overnight. $\mathrm{MnCO}_{3}$ particles were converted to $\mathrm{LiMn}_{2} \mathrm{O}_{4}$ particles through calcination after mixing stoichiometric quantities of $\mathrm{LiOH}$ in a Carbolite CWF 1300 box furnace in an air atmosphere at $800{ }^{\circ} \mathrm{C}$ for $5 \mathrm{~h}$.

\section{Material Characterization}


Powder X-ray diffraction was performed with a PANalytical X'Pert Pro MPD using

$\mathrm{CuK} \alpha$ radiation. Scanning electron microscopy (SEM) with an FEI Quanta 650 SEM was used to image all samples. Particle size distributions were obtained by analysis of SEM images with the program Image ${ }^{35}$.

\section{Electrochemical Characterization}

Electrochemical analysis was done using CR2032 coin cells with lithium metal anodes and cathodes containing the synthesized $\mathrm{LiMn}_{2} \mathrm{O}_{4}$ active material. The $\mathrm{LiMn}_{2} \mathrm{O}_{4^{-}}$ containing cathode was prepared by coating a slurry comprised of $\mathrm{LiMn}_{2} \mathrm{O}_{4}$ active material, carbon black conductive additive, and polyvinylidene diflouride binder in a weight ratio of 80:10:10 onto an aluminum current collector. The electrode slurry was dried in an $80{ }^{\circ} \mathrm{C}$ oven overnight and dried in an $80{ }^{\circ} \mathrm{C}$ vacuum oven for $3 \mathrm{~h}$ prior to punching out $14 \mathrm{~mm}$ electrode disks. The electrolyte used was $1.2 \mathrm{M} \mathrm{LiPF}_{6}$ dissolved in a solution containing 3:7 ethylene carbonate:ethyl methyl carbonate. Cells were cycled between a voltage window of 3.4 to $4.2 \mathrm{~V}$ vs $\mathrm{Li} / \mathrm{Li}^{+}$using a MACCOR battery tester.

\section{Results and Discussion}

In this study we specifically focused on the influence of solution chemistry on $\mathrm{MnCO}_{3}$ particle morphology. We designed our experiments to systematically vary both the total $\mathrm{Mn}^{2+}$ initially in solution (via total amount of $\mathrm{MnSO}_{4}$ salt originally dissolved in DI water) as well as the ratio of the dissolved transition metal to the coprecipitation agent. In our case, coprecipitation was facilitated by the $\mathrm{CO}_{3}{ }^{2-}$ from dissolved $\mathrm{NH}_{4} \mathrm{HCO}_{3}$. 
A representative example of the dramatic changes in $\mathrm{MnCO}_{3}$ particle morphology facilitated by changes in total initial $\mathrm{Mn}^{2+}$ concentration (with constant $\mathrm{NH}_{4} \mathrm{HCO}_{3}: \mathrm{MnSO}_{4}$ ratio of 40:1) can be found in the SEMs in Figure 1. At the lowest initial $\mathrm{Mn}^{2+}$ concentration $(1.5 \mathrm{mM})$, particles were relatively large at just under $10 \mu \mathrm{m}$ in average length of a particle side (Figure 1A). The particle surfaces appeared smooth and the overall shape was rhombohedral, with the wide angle measured to be $\sim 103^{\circ}$ from SEM images. It should be noted that this was similar to the rhombohedral angles reported for single $\mathrm{MnCO}_{3}$ crystals ${ }^{36}$. We also note that these particles have a large degree of clustering relative to others from the synthesis series shown in Figure 1, with particles often fused together. A slight increase in concentration from 1.5 to $3 \mathrm{mM}$ initial $\mathrm{Mn}^{2+}$ resulted in a transition from a rhombohedral morphology to a cubical morphology (Figure 1B). The cubical particles were approximately the same size and the surfaces were smooth, however all angles on the particles were now $\sim 90^{\circ}$ and it was rare to find the cubical particles attached or clustered together. An increase in $\mathrm{Mn}^{2+}$ concentration to 4.5 $\mathrm{mM}$ resulted in particles that are in a transition region between cubical and spherical particles (Figure 1C). The average particle size (an approximate diameter assuming they were spherical) is not significantly different from the rhombohedra or cubes, however, there were many edges and corners on the surfaces of the particles and there was a flaky, layered appearance to the surface resulting in a large degree of surface roughness. There was no longer an obvious 8 sharp corners on the particle surface. At $6 \mathrm{mM} \mathrm{Mn}^{2+}$, the resulting particles have transitioned to an approximately spherical morphology (Figure 1D). The diameters of the spherical particles were on approximately the same length scale as the particle length/diameters of the previously collected particles at lower $\mathrm{Mn}^{2+}$ 
concentrations. It was clear the overall spherical secondary particle morphology consisted of aggregates of smaller faceted particles that can be seen at the surfaces of the particles. A further increase in $\mathrm{Mn}^{2+}$ initial concentration to $7.5 \mathrm{mM}$ resulted in spherical particles as well (Figure 1E). These particles were also clearly made up of smaller primary particle aggregates that have agglomerated into a secondary structure that was approximately spherical. Relative to the spherical particles at the slightly lower $\mathrm{Mn}^{2+}$ concentration (Figure 1D), the average particle size has dropped significantly with the diameters decreasing by almost a factor of 4 (Figure 1E). Subsequent increases in initial $\mathrm{Mn}^{2+}$ concentration to $9 \mathrm{mM}$ (Figure 1F) and $10.5 \mathrm{mM}$ (Figure 1G) resulted in particle morphologies that were approximately spherical and similar to those found at $7.5 \mathrm{mM}$ (Figure 1E), although as the $\mathrm{Mn}^{2+}$ concentration was increased the average diameter of the particles decreased slightly. We note that a final synthesis was done at $12 \mathrm{mM}$ initial $\mathrm{Mn}^{2+}$ concentration; however, the particles were not recoverable for SEM characterization. A cartoon illustrating the transition from rhombohedral to cubical to transitionary cubical/spherical to spherical to decreasing diameter spherical is shown in Figure $1 \mathrm{H}$ to highlight the morphology changes from Figures 1A-G.

To gain further insights into the influence of reagent concentrations and solution chemistry on final $\mathrm{MnCO}_{3}$ precipitate particle morpohology, a series of experiments were conducted where the same sequence of increasing $\mathrm{Mn}^{2+}$ concentrations was used as described earlier (1.5 to $12 \mathrm{mM}$ in $1.5 \mathrm{mM}$ increments, as used in Figure 1), however, the $\mathrm{NH}_{4} \mathrm{HCO}_{3}: \mathrm{MnSO}_{4}$ ratio was varied as well with ratios of 10:1, 5:1, and 1:1 in addition to the 40:1 sequence described above. The detailed SEMs of the resulting particle 
morphologies can be found in the Supplemental Material in Figure S1 (10:1 reagent ratio), Figure S2 (5:1 reagent ratio), and Figure S3 (1:1 reagent ratio). The morphologies observed are summarized in the illustration in Figure 2A. At all $\mathrm{NH}_{4} \mathrm{HCO}_{3}: \mathrm{MnSO}_{4}$ ratios the general trend for change in morphology was the same, where for increasing $\mathrm{Mn}^{2+}$ concentrations the particles transitioned from rhombohedral and/or cubical morphologies to a cubical/spherical transitional morphology to large spherical particles to decreasing sizes of spherical particles. Also, as the $\mathrm{NH}_{4} \mathrm{HCO}_{3}: \mathrm{MnSO}_{4}$ ratio decreased, the location of the cubical-to-spherical transition moved to higher initial $\mathrm{Mn}^{2+}$ reagent concentrations. At the lower $\mathrm{NH}_{4} \mathrm{HCO}_{3}: \mathrm{MnSO}_{4}$ ratios, recovery of samples with the lowest concentrations of initial $\mathrm{Mn}^{2+}$ became less likely.

Figure 2B displays the average particle size at the variety of synthesis conditions explored. Size was defined as the characteristic length of the particles (edge length for cubical or rhombohedral particles and diameter for transitional particles and spherical particles). The results displayed in Figure 2 demonstrate the diversity of particle morphologies and sizes that were accessible from the solution chemistry conditions investigated. The size range for smooth cubical/rhombohedral particles was 6-12 $\mu \mathrm{m}$. Transitional cubical/spherical rough particles ranged in size from 8-12 $\mu \mathrm{m}$. Spheres were synthesized in sizes ranging from $1-15 \mu \mathrm{m}$. We note that the polydispersity of these particles was very low compared to coprecipitation battery precursor synthesis typically reported in the literature, ${ }^{13,32,33}$ with many of our synthesized particle population polydispersities $<10 \%$ (see Supplemental Material Figure S4 for polydispersity of all reported samples). 
The morphology transitions observed in our solution synthesis were consistent with tuning the nucleation and growth of the $\mathrm{MnCO}_{3}$ particles within the range of concentrations explored. At the lowest $\mathrm{Mn}^{2+}$ concentrations, the synthesis had the longest inoculation times (inoculation time being the time elapsed between mixing and visible precipitation in the beaker) indicating a slow growth of the precipitates. In this slow growth limit particles also had sharp angles that deviated from the $90^{\circ}$ degree cubical particles and began to approach the wide rhombohedral angle of rhodochrosite $\left(\mathrm{MnCO}_{3}\right)$, which has been reported as $103^{\circ}{ }^{36}$ The slow growth of the particles and angles of the particles observed being around $103^{\circ}$ was consistent with the particles approaching the single crystal limit of $\mathrm{MnCO}_{3}$ (Figure 1A), thus it was likely that these particles were single rhodochrosite crystals. At increasing $\mathrm{Mn}^{2+}$ concentrations, inoculation times were always observed to decrease. The cubical particles have slightly faster inoculation times, and thus with the faster growth the angles observed on the particles were all $\sim 90^{\circ}$ and the full $103^{\circ}$ rhombohedral angle was not observed (Figure 1B). At further increases in concentration, the decreased inoculation time would result in more small nuclei precipitates being formed. At the highest $\mathrm{Mn}^{2+}$ concentrations, this would be consistent with the decrease in spherical particle size observed for increasing $\mathrm{Mn}^{2+}$ concentrations (Figures 1D-G). With more nuclei being produced because of the high initial precipitate reagent concentration, there was less reagent available for growth on a per particle basis and thus the final resulting particles were smaller for higher reagent concentrations. Correlations between higher nuclei density and smaller final particle populations have previously been reported for $\mathrm{MnCO}_{3}$ synthesis. ${ }^{30}$ It is important to note, however, that our 
spherical particles were agglomerates of these smaller nuclei. The formation of the spherical particles results from a complex process of nucleation of primary particles and their assembly into a secondary spherical morphology. The details of the formation process of the spherical aggregates and the kinetics associated with these assemblies are still unknown, however, previous reports in the literature have attributed the onset of the spherical particle morphology to colloidal forces, in particular electrostatic interactions. ${ }^{9}$ The transitional particles were an intermediate zone between the slow growth rhombohedral/cubical particles and the agglomerated small nuclei spherical particles. We speculate the substantial roughness at the surface is due to the agglomeration of partially formed slower-growing particles. Also of note was that an increase in $\mathrm{NH}_{4} \mathrm{HCO}_{3}: \mathrm{MnSO}_{4}$ ratio decreases inoculation time and shifts the particle morphology transitions to lower $\mathrm{Mn}^{2+}$ concentrations. This is also consistent with the interplay between the number of nuclei formed as the solubility of $\mathrm{MnCO}_{3}$ is dependent on both the $\mathrm{Mn}^{2+}$ concentration and the $\mathrm{CO}_{3}{ }^{2-}$ concentration, thus increasing the relative $\mathrm{NH}_{4} \mathrm{HCO}_{3}: \mathrm{MnSO}_{4}$ ratio increases the nucleation rate by driving precipitation forward faster.

It is important to understand the morphologies we have reported in the context of typical carbonate battery precursors reported in the literature. First, all of our synthesis was at relatively low concentrations specifically such that we could assess the interplay between solution chemistry and morphology by accessing these different nucleation and growth regimes. While our synthesis does not exceed $12 \mathrm{mM} \mathrm{Mn}^{2+}$ concentration, $2 \mathrm{M}$ concentrations of $\mathrm{Mn}^{2+}$ and other transition metal ions are not uncommon for carbonate battery precursors in the literature ${ }^{19}$. Our low concentrations allow us to access the 
diversity of morphologies reported, and also enable us to generate particle populations with relatively low polydispersity. Another important consideration in precursor synthesis that we were not explicitly investigating in this study was stir rate. Multiple coprecipitation battery precursor studies in the literature have investigated stir rate effects on morphology and/or final material performance. ${ }^{18,37}$ We will only comment here that changing stir rate also influenced our particle morphologies. An increase in impeller rpm from 500 to $4800 \mathrm{rpm}$ resulted in particles that, though clefted, were spherical in overall morphology at synthesis conditions that would give cubical morphology particles at 500 rpm (see Supplemental Material, Figure S5). The detailed origins of the mixing-induced morphology transitions are not yet completely understood and will be an area of future investigations.

The presence of an ammonium/ammonia source has previously been reported as being critical in morphology control of transition metal carbonate and hydroxide particles. ${ }^{19,34}$ We similarly found the presence of an ammonia source to be crucial. Replacement of our typical $\mathrm{NH}_{4} \mathrm{HCO}_{3}$ coprecipitation reagent with $\mathrm{NaHCO}_{3}$ resulted in dramatically reduced inoculation times and rapid formation of polydisperse particles (see Supplemental Material, Figure S6 for SEMs from a representative synthesis where $\mathrm{NH}_{4} \mathrm{HCO}_{3}$ was substituted for and equal concentration of $\mathrm{NaHCO}_{3}$ ). Ammonia has been shown to play a role in the coprecipitation of a variety of transition metals due to its ability to form aqueous soluble complexes with the transition metals. ${ }^{34}$ These complexes have previously been reported to play a major role in the synthesis of transition metal hydroxide particles, in particular by enabling dissolution/recrystallization of the precipitates which facilitated 
ripening of particles into larger secondary particles ${ }^{34}$. To understand whether ammonia complexation was facilitating dissolution/recrystallization in our system, we performed calculations of the equilibrium concentrations of the solution species found in our system using the Medusa solution chemistry diagrams software. The equilibrium constants and major reactions associated with our synthesis are listed in Table 1. Figure 3 shows the calculated equilibrium concentration of aqueous manganese species for all coprecipitation conditions tested. The dissolved manganese species are presented both in terms of total Mn solution concentration (Figure 3A) and as a fraction of the Mn that was available in the reaction vessel (Figure 3B). Total aqueous $\mathrm{Mn}$ species included were $\mathrm{Mn}^{+2}$, $\mathrm{MnHCO}_{3}{ }^{+}, \mathrm{Mn}\left(\mathrm{NH}_{3}\right)^{+2}, \mathrm{Mn}\left(\mathrm{NH}_{3}\right)_{2}{ }^{+2}$, and $\mathrm{MnOH}^{+}$. The neutral $\mathrm{pH}(\sim 7.5$ for all synthesis conditions) normally results in minimal $\mathrm{NH}_{3}$, with $\mathrm{NH}_{4}{ }^{+}$being the dominant ammonia species in solution. Thus, the calculated $\mathrm{Mn}\left(\mathrm{NH}_{3}\right)^{+2}$ concentration was low for all conditions synthesized. Regardless of conditions used, at equilibrium our calculations predicted that soluble manganese species make up no more than $0.1 \%$ of total manganese in solution. Therefore, we conclude that ripening through aqueous dissolution and recrystallization of $\mathrm{MnCO}_{3}$ in our system was unlikely. The results of Figure 3 are also presented in table form in Table S1 and Table S2.

Further evidence that long-term dissolution and recrystallization does not play a major role in particle morphology for our system was provided through particle ripening experiments. We performed two coprecipitations using experimental conditions that gave us cubical and spherical particle morphologies, respectively (Figure 1B and Figure S1D). In these experiments, however, the particles were allowed to age for 7 hours instead of 
being collected after 0.5 hours. SEMs from the long-time coprecipitations can be found in Supplemental Material Figure S7. Over the 7 hour synthesis, the overall particle morphology does not change substantially relative to 0.5 hours. In the spherical particle case, only minor changes in surface roughness were observed, but there were no significant changes in overall particle size or shape. Cubical particles undergo no noticeable morphological changes.

While equilibrium calculations suggest ammonia-complex enabled dissolution/recrystallization does not facilitate long-term ripening and morphology changes, control experiments where ammonia was substituted with sodium (Figure S6) suggest that ammonia does play a role controlling particle morphology. One possibility was that even though the ammonia provides a relatively small amount of complexation of the manganese in solution, it was sufficient to lower supersaturation of the $\mathrm{MnCO}_{3}$ enough to influence the nucleation and growth of $\mathrm{MnCO}_{3}$ precipitates during the crucial early stages of the coprecipitation synthesis. We have qualitatively observed that the overall particle morphologies were frequently completed within the first few minutes of mixing of the reagent solutions. Detailed studies of the formation rates of $\mathrm{MnCO}_{3}$ during the early stages of the coprecipitation will be necessary to ascertain the role that ammonia was playing at early synthesis stages to facilitate $\mathrm{MnCO}_{3}$ final morphology.

The detailed $\mathrm{MnCO}_{3}$ synthesis studies described above were undertaken in an effort to achieve control over a diversity of morphologies and sizes of lithium-ion battery precursor particles. For these precursors to be useful in providing lithium-ion battery final 
active materials of tunable morphology, they must be able to retain their morphology after calcination and lithiation to convert the precursors to lithium-ion battery final active material. ${ }^{3,9}$ To demonstrate that a variety of morphologies of active materials could be obtained via this route we chose two extremes in $\mathrm{MnCO}_{3}$ precursor morphology, spherical and cubical, for conversion to $\mathrm{LiMn}_{2} \mathrm{O}_{4}$. As is shown in Figure 4, the spherical $\mathrm{MnCO}_{3}$ (Figure 4A) was successfully converted to spherical $\mathrm{LiMn}_{2} \mathrm{O}_{4}$ (Figure 4B) while retaining its overall spherical morphology and without sintering together into larger aggregates. Similarly, the cubical $\mathrm{MnCO}_{3}$ (Figure 4C) was converted to cubical $\mathrm{LiMn}_{2} \mathrm{O}_{4}$ without significant fusing of particles into larger aggregates and while retaining the overall cubical morphology. Powder X-ray diffraction confirmed the full conversion to spinel $\mathrm{LiMn}_{2} \mathrm{O}_{4}$ (Figure S8).

As a final confirmation of our $\mathrm{MnCO}_{3}$ carbonate precursors as templates for tunable morphology lithium-ion battery cathode materials, we fabricated coin cells with cathodes comprised of the spherical and cubical $\mathrm{LiMn}_{2} \mathrm{O}_{4}$ particles shown in Figures 4B and 4D. The $\mathrm{Li} / \mathrm{LiMn}_{2} \mathrm{O}_{4}$ half cells were cycled at increasing rates of $\sim \mathrm{C} / 20, \mathrm{C} / 10, \mathrm{C} / 2$, and $1 \mathrm{C}$ (the $1 \mathrm{C}$ rate used for cycling was determined from using $148.2 \mathrm{~mA} / \mathrm{g}$ of active $\mathrm{LiMn}_{2} \mathrm{O}_{4}$ material, the same rate was used on charge and discharge) between $3.4 \mathrm{~V}$ (vs. Li) to $4.2 \mathrm{~V}$ (vs. Li). Figure 5 shows the second charge/discharge cycle at $\mathrm{C} / 20$ for cathodes comprised of the spherical (Figure 5A) and cubical (Figure 5B) particles. The discharge capacities at the various rates can be found in the Supplemental Material, Figure S9. The charge/discharge characteristics of both the spherical (Figure 5A) and cubical (Figure 5B) $\mathrm{LiMn}_{2} \mathrm{O}_{4}$ active materials were consistent with those previously reported in the 
literature, ${ }^{25}$ with two voltage plateaus at roughly $4.0 \mathrm{~V}$ and $4.1 \mathrm{~V}$. Both coulombic and round trip energy efficiency for the cells was very high (>98\% coulombic efficiency and $>97 \%$ round trip energy efficiency at $\mathrm{C} / 20$ ), and the initial capacity $>115 \mathrm{mAh} / \mathrm{g}$ for both materials. The spherical particles had slightly better rate capability and the cubical particles had slightly higher initial and low rate gravimetric capacity, however, it would be premature to assign these observations at this point directly to the influences of particle morphology.

\section{Conclusions}

The influence of solution chemistry on resulting particle morphology during the synthesis of $\mathrm{MnCO}_{3}$ precipitates was investigated in detail. It was found that moderate changes in reagent concentration could be used to tune the morphology and size of $\mathrm{MnCO}_{3}$ particles, with shapes including rhombohedral, cubical, spherical, and cubical/spherical transitional and sizes ranging from 1 to $15 \mu \mathrm{m}$. These particles were very monodisperse relative to other common battery precursor particles reported in the literature. The resulting $\mathrm{MnCO}_{3}$ morphologies were correlated with inoculation times and nucleation and growth of initial precipitates and appear to not be influenced by long-period dissolution/recrystallization processes, in contrast to processes that facilitate other precipitate systems in the literature. The controlled-morphology $\mathrm{MnCO}_{3}$ precursors tuned via solution chemistry were used as templates to produce $\mathrm{LiMn}_{2} \mathrm{O}_{4}$, a lithium-ion battery cathode material. Synthesized $\mathrm{LiMn}_{2} \mathrm{O}_{4}$ particles retained the morphology of the $\mathrm{MnCO}_{3}$ precursors, demonstrating that the described solution synthesis can be used to produce a diversity of controllable sizes and morphologies of lithium-ion battery active materials. 


\section{Acknowledgements}

This research was partially supported by the National Science Foundation through award ECCS-1405134 and by start-up support at the University of Virginia. 


\section{References}

1. Thackeray, M. M., Wolverton, C. \& Isaacs, E. D. Electrical energy storage for transportation - approaching the limits of, and going beyond, lithium-ion batteries. Energy Environ. Sci. 5, 7854 (2012).

2. Goodenough, J. B. \& Kim, Y. Challenges for Rechargeable Li Batteries †. Chem. Mater. 22, 587-603 (2010).

3. Koenig, G. M., Belharouak, I., Deng, H., Sun, Y. \& Amine, K. Composition-Tailored Synthesis of Gradient Transition Metal Precursor Particles for Lithium-Ion Battery Cathode Materials. Chem. Mater. 23, 1954-1963 (2011).

4. Belharouak, I., Koenig, G. M. \& Amine, K. Electrochemistry and safety of Li4Ti5O12 and graphite anodes paired with LiMn2O4 for hybrid electric vehicle Li-ion battery applications. J. Power Sources 196, 10344-10350 (2011).

5. Zhao, C., Kang, W., Wang, X., Zhao, S. \& Shen, Q. Sacrificial templating synthesis of rod-like LiNixMn2-xO4 spinels and their improved cycling performance. Micro Nano Lett. 7, 558 (2012).

6. Kim, D. K. et al. Spinel LiMn 2 O 4 Nanorods as Lithium Ion Battery Cathodes. Nano Lett. 8, 3948-3952 (2008).

7. Lin, H. B. et al. Porous LiMn2O4 cubes architectured with single-crystalline nanoparticles and exhibiting excellent cyclic stability and rate capability as the cathode of a lithium ion battery. J. Mater. Chem. A 2, 9272 (2014).

8. Taniguchi, I. \& Bakenov, Z. Spray pyrolysis synthesis of nanostructured LiFexMn2-xO4 cathode materials for lithium-ion batteries. Powder Technol. 159, 55-62 (2005).

9. Wang, D., Belharouak, I., Koenig, G. M., Zhou, G. \& Amine, K. Growth mechanism of $\mathrm{NiO} .3 \mathrm{Mn} 0.7 \mathrm{CO} 3$ precursor for high capacity Li-ion battery cathodes. J. Mater. Chem. 21, 9290 (2011).

10. Wang, B., Wu, X.-L., Shu, C.-Y., Guo, Y.-G. \& Wang, C.-R. Synthesis of CuO/graphene nanocomposite as a high-performance anode material for lithium-ion batteries. J. Mater. Chem. 20, 10661 (2010).

11. Mei, R., Song, X., Yang, Y., An, Z. \& Zhang, J. Plate-like LiFePO4 crystallite with preferential growth of (010) lattice plane for high performance $\mathrm{Li}$-ion batteries. $R S C A d v$. 4, 5746 (2014).

12. Li, Z., Xu, J., Chen, X., Zhou, Q. \& Shang, T. A simple hydrothermal route to synthesis of rod-like MnOOH and spindle-shaped MnCO3. Colloid Polym. Sci. 289, 1643-1651 (2011). 
13. Ryu, W.-H., Lim, S.-J., Kim, W.-K. \& Kwon, H. 3-D dumbbell-like LiNi1/3Mn1/3Co1/3O2 cathode materials assembled with nano-building blocks for lithium-ion batteries. J. Power Sources 257, 186-191 (2014).

14. Hong, S.-K., Mho, S.-I., Yeo, I.-H., Kang, Y. \& Kim, D.-W. Structural and electrochemical characteristics of morphology-controlled Li[Ni0.5Mn1.5]O4 cathodes. Electrochim. Acta 156, 29-37 (2015).

15. Koenig, G. M., Belharouak, I., Wu, H. M. \& Amine, K. Hollow lithiated metal oxide particles as lithium-ion battery cathode materials. Electrochim. Acta 56, 1426-1431 (2011).

16. Ebner, M., Chung, D.-W., García, R. E. \& Wood, V. Tortuosity Anisotropy in LithiumIon Battery Electrodes. Adv. Energy Mater. 4, n/a-n/a (2014).

17. Matsuda, K. \& Taniguchi, I. Relationship between the electrochemical and particle properties of LiMn2O4 prepared by ultrasonic spray pyrolysis. J. Power Sources 132, 156-160 (2004).

18. Lee, M.-H., Kang, Y.-J., Myung, S.-T. \& Sun, Y.-K. Synthetic optimization of $\mathrm{Li}[\mathrm{Ni1} / 3 \mathrm{Co} 1 / 3 \mathrm{Mn} 1 / 3] \mathrm{O} 2$ via co-precipitation. Electrochim. Acta 50, 939-948 (2004).

19. Park, S.-H., Kang, S.-H., Belharouak, I., Sun, Y. K. \& Amine, K. Physical and electrochemical properties of spherical $\mathrm{Li} 1+\mathrm{x}(\mathrm{Ni1} / 3 \mathrm{Co} 1 / 3 \mathrm{Mn} 1 / 3) 1-\mathrm{xO} 2$ cathode materials. J. Power Sources 177, 177-183 (2008).

20. Wang, T., Liu, Z.-H., Fan, L., Han, Y. \& Tang, X. Synthesis optimization of $\mathrm{Li} 1+\mathrm{x}[\mathrm{Mn} 0.45 \mathrm{Co} 0.40 \mathrm{Ni} 0.15] \mathrm{O} 2$ with different spherical sizes via co-precipitation. Powder Technol. 187, 124-129 (2008).

21. Zhang, S., Deng, C., Fu, B. L., Yang, S. Y. \& Ma, L. Synthetic optimization of spherical $\mathrm{Li}[\mathrm{Ni} 1 / 3 \mathrm{Mn} 1 / 3 \mathrm{Co} 1 / 3] \mathrm{O} 2$ prepared by a carbonate co-precipitation method. Powder Technol. 198, 373-380 (2010).

22. Li, L. et al. A simple and effective method to synthesize layered LiNi0.8Co0.1Mn0.1O2 cathode materials for lithium ion battery. Powder Technol. 206, 353-357 (2011).

23. Tarascon, J. M. et al. Synthesis Conditions and Oxygen Stoichiometry Effects on Li Insertion into the Spinel LiMn O. J. Electrochem. Soc. 141, 1421-1431 (1994).

24. Ferg, E. \& Gummow, R. Spinel Anodes for Lithium-Ion Batteries. J. Electrochem. Soc. 141, 9-12 (1994).

25. Tarascon, J. \& Wang, E. The Spinel Phase of LiMn2 O 4 as a Cathode in Secondary Lithium Cells. J. Electrochem. Soc. 138, 1-6 (1991). 
26. Xie, X. et al. Growth and morphology of nanometer LiMn2O4 powder. Powder Technol. 169, 143-146 (2006).

27. Michalska, M. et al. Influence of $\mathrm{LiMn} 2 \mathrm{O} 4$ modification with $\mathrm{CeO} 2$ on electrode performance. Electrochim. Acta 136, 286-291 (2014).

28. Duan, X., Ma, J., Lian, J., Kim, T. \& Zheng, W. A novel surfactant-free route to MnCO3 steep rhombohedra crystals and their large-scale assembly into regular elongated patterns in a mixed solvent. Chem. Commun. (Camb). 46, 7133-5 (2010).

29. Hamada, S., Kudo, Y., Okada, J. \& Kano, H. Preparation of Monodispersed Manganese ( IV ) Oxide Particles from Manganese ( 11 ) Carbonate Formation of Monodispersed Spherical Manganese ( II ) Carbonate Particles Preparation of Monoclinic-Like Manganese To determine the zeta potential and surface. J. Colloid Interface Sci. 118, 356-365 (1987).

30. Zhu, H., Stein, E. W., Lu, Z., Lvov, Y. M. \& McShane, M. J. Synthesis of Size-Controlled Monodisperse Manganese Carbonate Microparticles as Templates for Uniform Polyelectrolyte Microcapsule Formation. Chem. Mater. 17, 2323-2328 (2005).

31. Lee, H.-K., Sakemi, D., Selyanchyn, R., Lee, C.-G. \& Lee, S.-W. Titania nanocoating on $\mathrm{MnCO} 3$ microspheres via liquid-phase deposition for fabrication of template-assisted core-shell- and hollow-structured composites. ACS Appl. Mater. Interfaces 6, 57-64 (2014).

32. Wan, C., Cheng, M. \& Wu, D. Synthesis of spherical spinel LiMn2O4 with commercial manganese carbonate. Powder Technol. 210, 47-51 (2011).

33. Zhu, Z., Zhang, D. \& Yu, H. Preparation of spherical hierarchical LiNi0.5Mn1.5O4 with high electrochemical performances by a novel composite co-precipitation method for $5 \mathrm{~V}$ lithium ion secondary batteries. Electrochim. Acta 115, 290-296 (2014).

34. Bommel, A. Van \& Dahn, J. of the Growth Mechanism of Coprecipitated Spherical and Dense Nickel, Manganese, and Cobalt-Containing Hydroxides in the Presence of Aqueous Ammonia. Chem. Mater. 21, 1500-1503 (2009).

35. Schneider, C. a, Rasband, W. S. \& Eliceiri, K. W. NIH Image to ImageJ: 25 years of image analysis. Nat. Methods 9, 671-675 (2012).

36. Wayland, R. G. Composition, Specific Gravity, and Refractive Indices of Rhodochrosite; Rhodochrosite from Butte, Montana. Am. Mineral. 27, 614-628 (1942).

37. Camardese, J., Abarbanel, D. W., McCalla, E. \& Dahn, J. R. Synthesis of Spherical CoreShell Ni(OH)2-Ni1/2Mn1/2(OH)2 Particles via a Continuously Stirred Tank Reactor. $J$. Electrochem. Soc. 161, A890-A895 (2014). 
38. Lesht, D. \& Bauman, J. E. Thermodynamics of the Manganese(I1) Bicarbonate System. Inorg. Chem. 17, 3332-3334 (1978). 


\section{Figure Captions}

Figure 1. SEM images of $\mathrm{MnCO}_{3}$ particles prepared with a 40:1 ratio of $\mathrm{NH}_{4} \mathrm{HCO}_{3}$ to $\mathrm{MnSO}_{4}$ and ascending concentration of $\mathrm{MnSO}_{4}$ : (A) $1.5 \mathrm{mM} \mathrm{MnSO}_{4}$, (B) $3 \mathrm{mM} \mathrm{MnSO}_{4}$, (C) $4.5 \mathrm{mM}$ $\mathrm{MnSO}_{4}$, (D) $6 \mathrm{mM} \mathrm{MnSO}_{4}$, (E) $7.5 \mathrm{mM} \mathrm{MnSO}_{4}$, (F) $9 \mathrm{mM} \mathrm{MnSO}_{4}$, (G) $10.5 \mathrm{mM} \mathrm{MnSO}_{4}$. The particles from the $12 \mathrm{mM}$ synthesis were not recoverable. Scale bars correspond to $20 \mu \mathrm{m}$. (H) Illustration of general shape and size transition of $\mathrm{MnCO}_{3}$ at progressively higher concentration.

Figure 2. (A) Ilustrations of morphology of $\mathrm{MnCO}_{3}$ particles at prescribed synthesis conditions. Squares represent primarily rhombohedral or cubical particles, jagged squares represent cubical/spherical transitional particles, circles represent primarily spherical particles, and small circles represent small spherical particles. Blank locations denote conditions where particles were not recoverable. (B) Volume weighted average particle size (characteristic length defined in text) at prescribed synthesis conditions. Standard deviations of particle sizes can be found in Supplemental Material Figure S4.

Table 1. Equilibrium and solubility product constants $(\mathrm{K})$ for selected reactions involved in $\mathrm{MnCO}_{3}$ coprecipitation. ${ }^{34,38}$

Figure 3. (A) Total calculated fraction of manganese that remains soluble at equilibrium as a function of total initial $\mathrm{MnSO}_{4}$ concentration. Relative $\mathrm{NH}_{4} \mathrm{HCO}_{3}: \mathrm{MnSO}_{4}$ ratios used in the calculations were 5:1 (top curve), 10:1 (middle curve), 40:1 (bottom curve) (B) Calculated fraction of all manganese available in solution which was soluble at equilibrium as a function of total initial $\mathrm{MnSO}_{4}$ concentration. Relative $\mathrm{NH}_{4} \mathrm{HCO}_{3}: \mathrm{MnSO}_{4}$ ratios used in the calculations were 5:1 (top curve), 10:1 (middle curve), 40:1 (bottom curve). 
Figure 4. SEM images of (A) spherical $\mathrm{MnCO}_{3}$ precursor particles and (B) the same particles after calcination to spherical $\mathrm{LiMn}_{2} \mathrm{O}_{4}$; and (C) cubical $\mathrm{MnCO}_{3}$ precursor particles and (D) the same particles after calcination to cubical $\mathrm{LiMn}_{2} \mathrm{O}_{4}$. Scale bars correspond to $20 \mu \mathrm{m}$.

Figure 5. Charge/discharge curves from the second cycle of $\mathrm{Li} / \mathrm{LiMn}_{2} \mathrm{O}_{4}$ half cells with cathodes containing $\mathrm{LiMn}_{2} \mathrm{O}_{4}$ active material particles with morphologies which are predominantly (A) spherical and (B) cubical. The rate of charge/discharge for both cells was approximately $\mathrm{C} / 20$. 

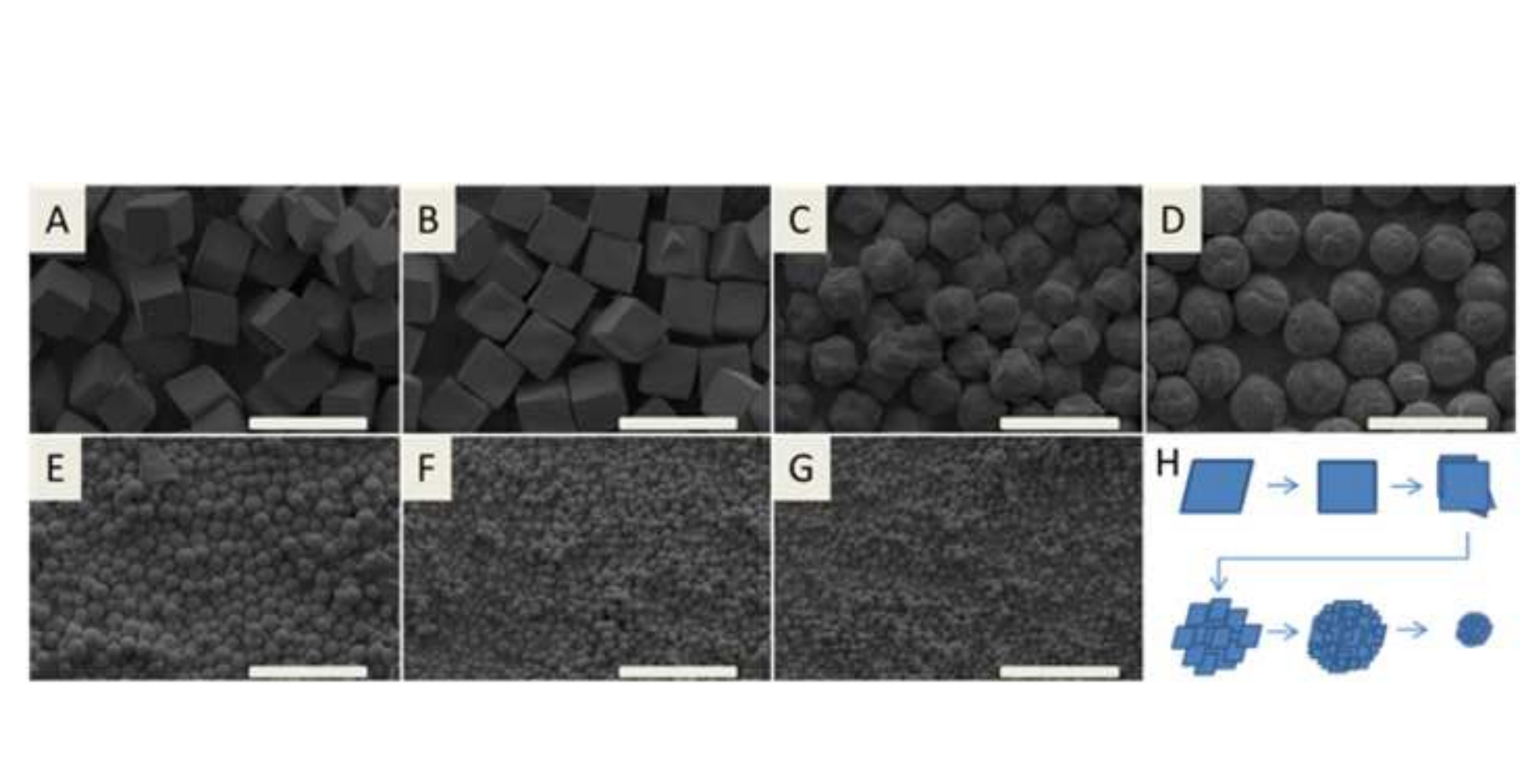

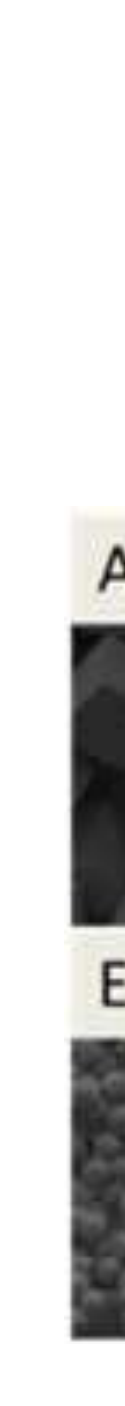

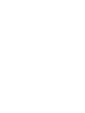



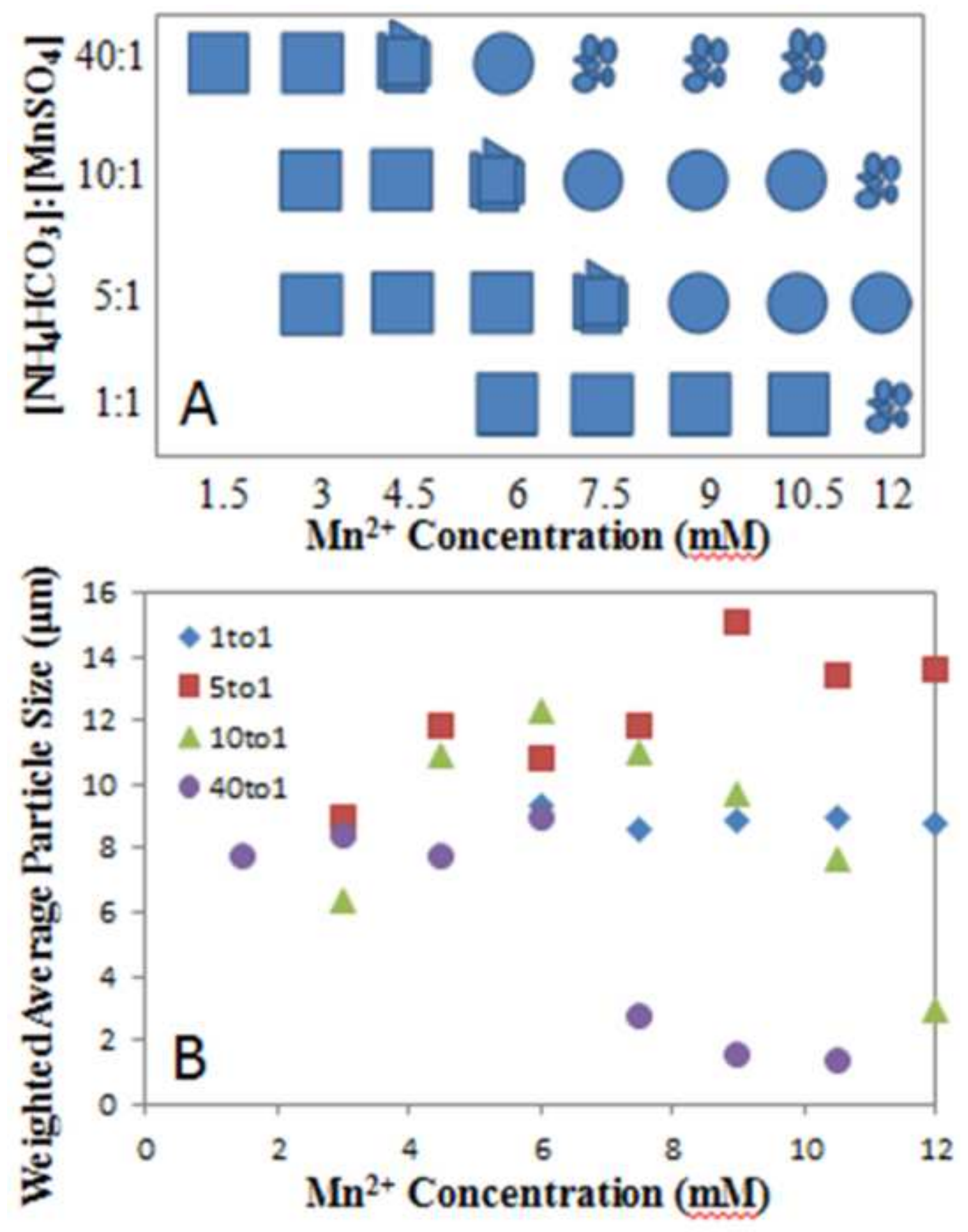

Figure 2 

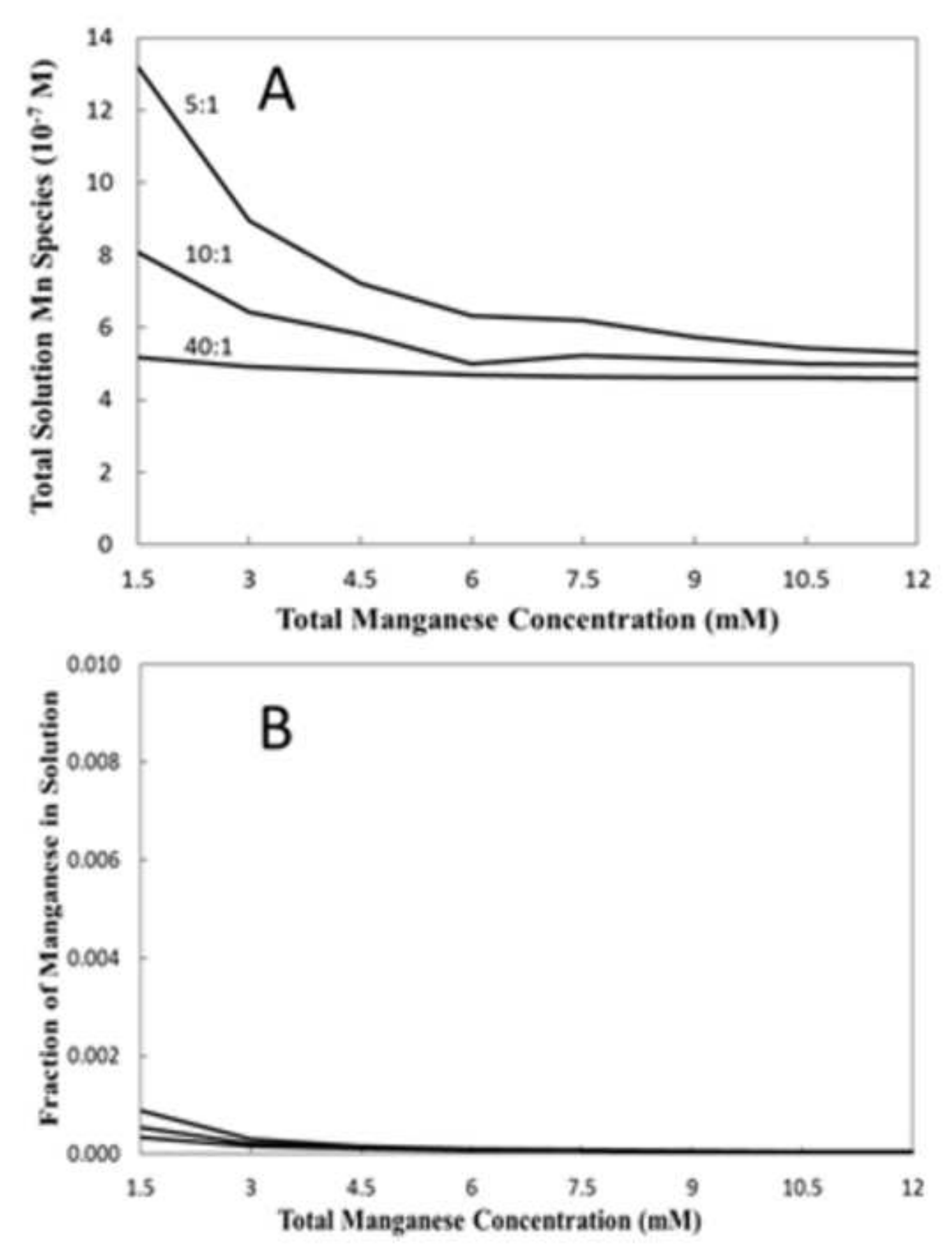

Figure 3

(⿸丆口

\section{3}

\section{.}

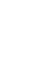
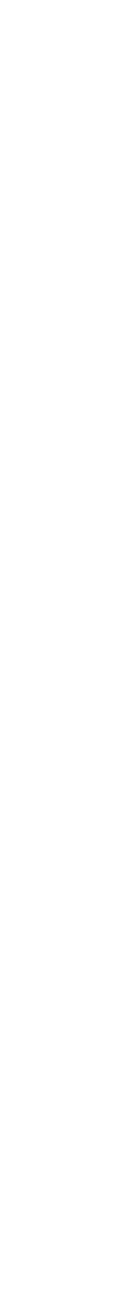

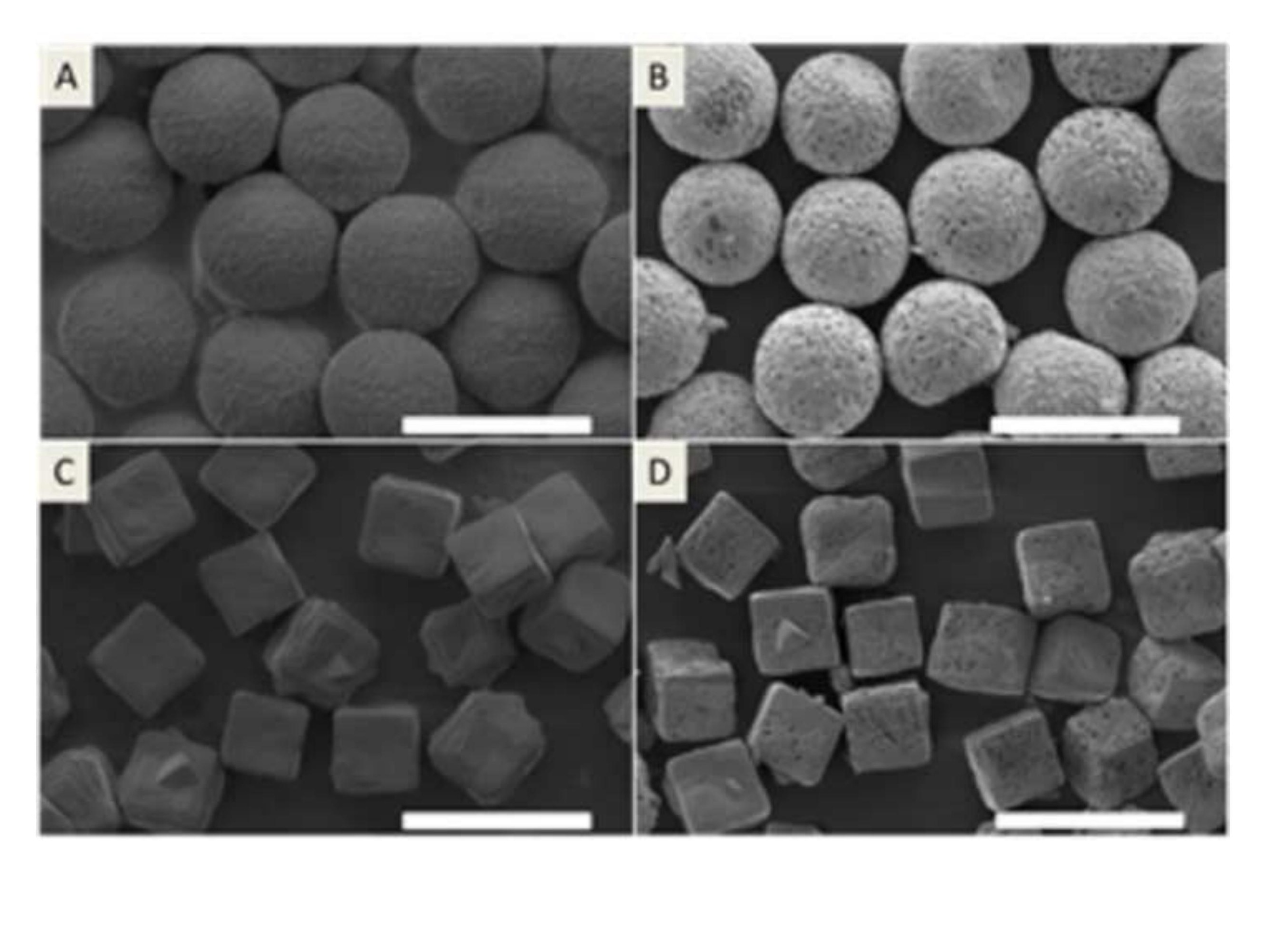


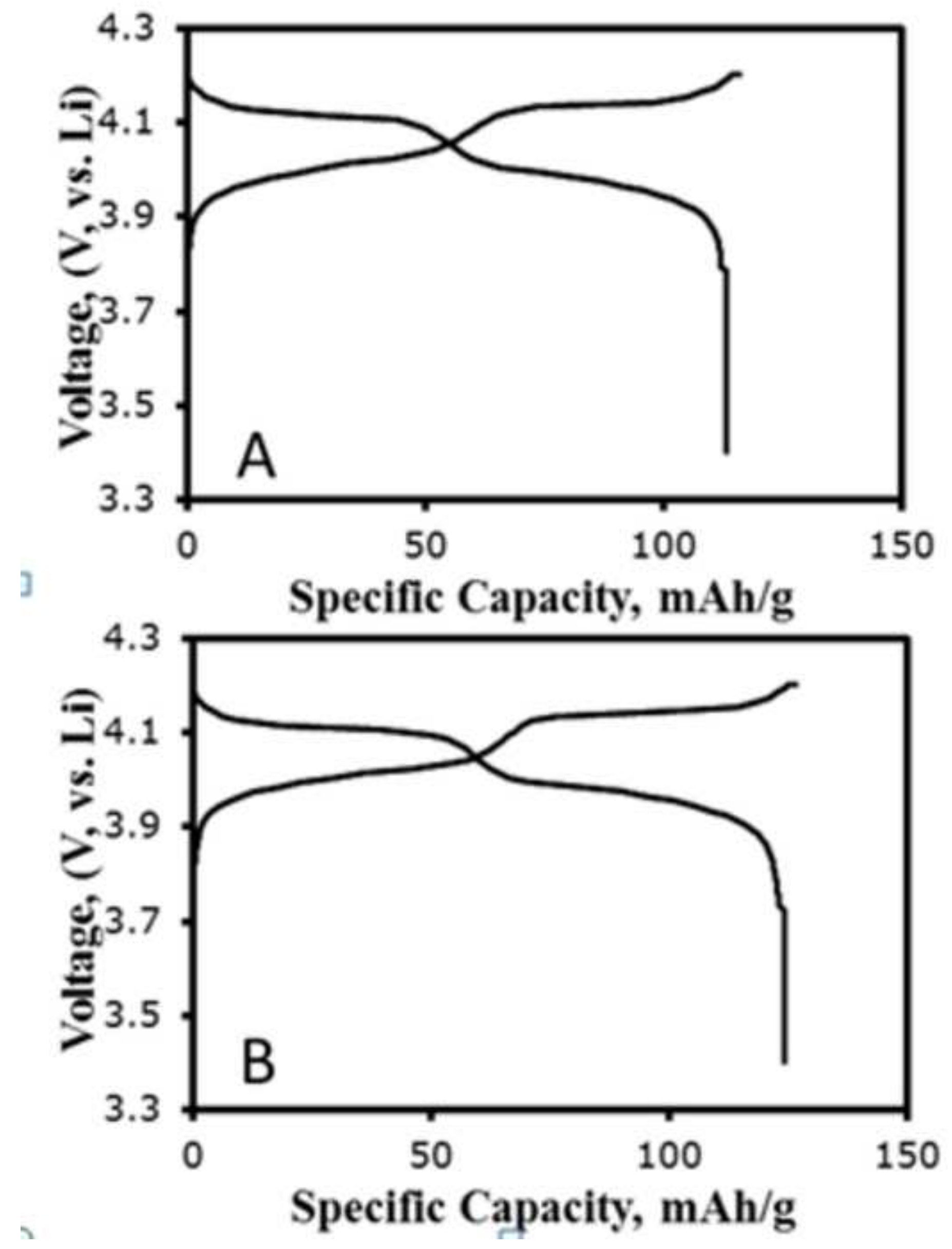

了

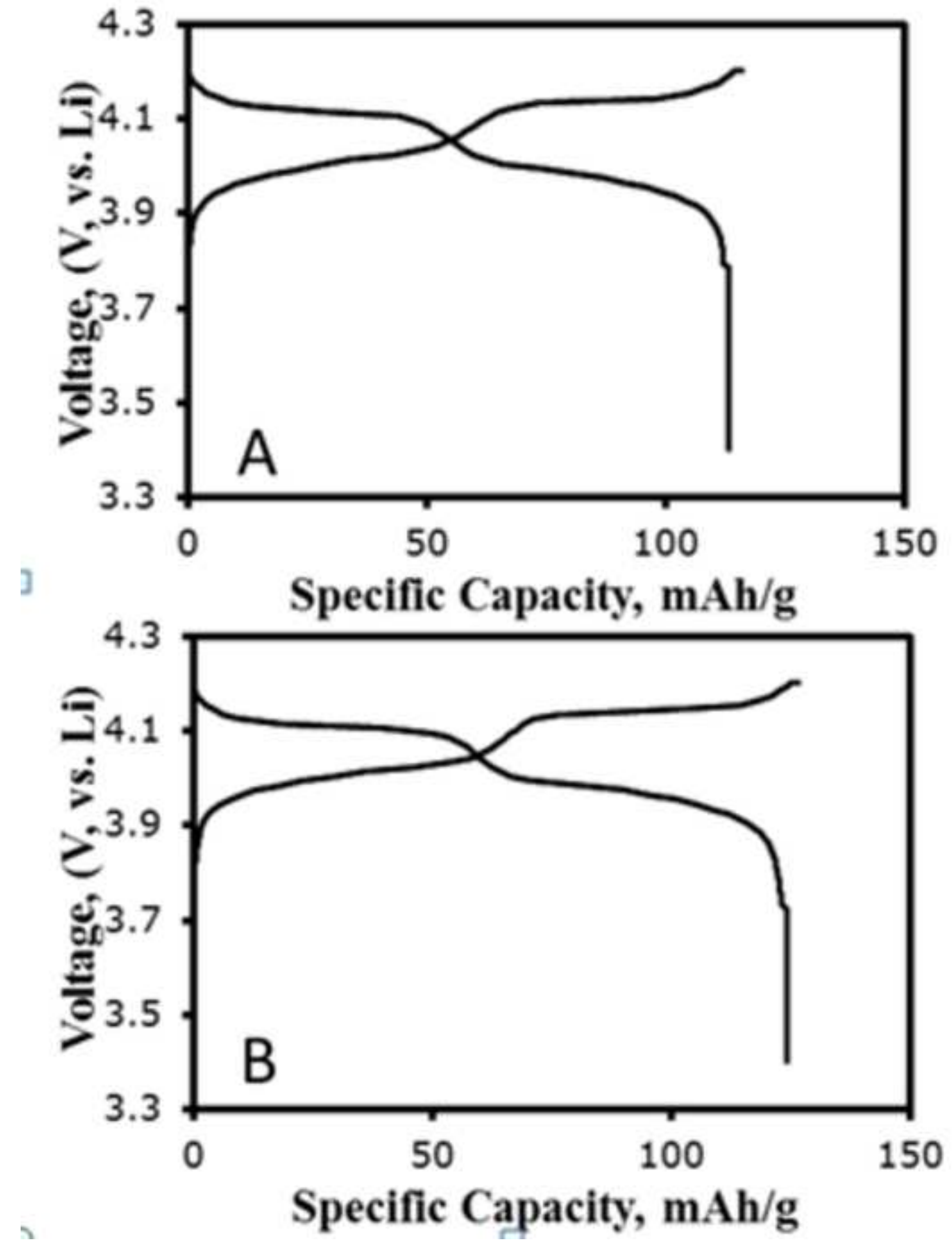

Figure 5

5
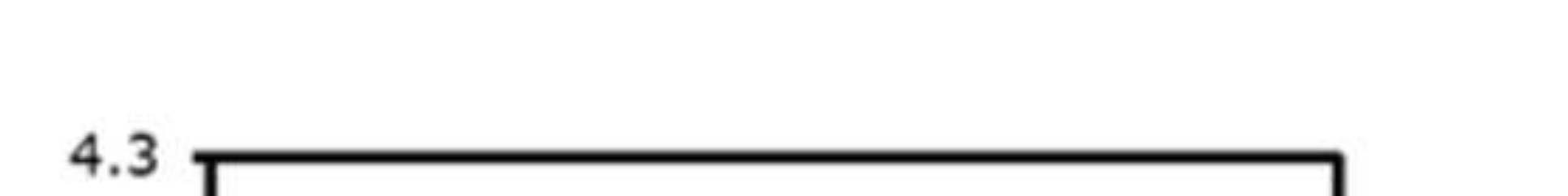

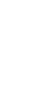

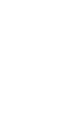

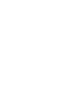

政
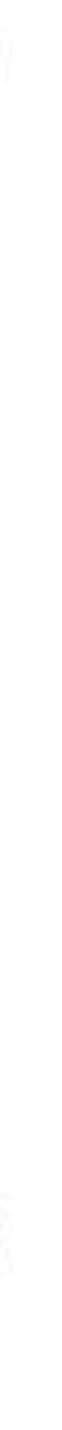

Specific Capacity, mAh/g 
Equilibrium Reaction$$
\mathrm{Mn}^{+2}+\mathrm{NH}_{3} \rightleftharpoons\left[\mathrm{Mn}\left(\mathrm{NH}_{3}\right)\right]^{2}
$$$$
\mathrm{Mn}^{+2}+2 \mathrm{NH}_{3} \rightleftharpoons\left[\mathrm{Mn}\left(\mathrm{NH}_{3}\right)_{2}\right]^{2}
$$$$
\mathrm{Mn}^{+2}+3 \mathrm{NH}_{3} \rightleftharpoons\left[\mathrm{Mn}\left(\mathrm{NH}_{3}\right)_{3}\right]^{2}
$$$$
\mathrm{Mn}^{+2}+4 \mathrm{NH}_{3} \rightleftharpoons\left[\mathrm{Mn}\left(\mathrm{NH}_{3}\right)_{4}\right]^{2}
$$$$
\mathrm{NH}_{3}+\mathrm{H}_{2} \mathrm{O} \rightleftharpoons \mathrm{NH}_{4}^{+}+\mathrm{OH}^{-}
$$$$
\mathrm{MnCO}_{3} \rightleftharpoons \mathrm{Mn}^{2+}+\mathrm{CO}_{3}^{-2}
$$$$
\mathrm{Mn}(\mathrm{OH})_{2} \rightleftharpoons \mathrm{Mn}^{2+}+2 \mathrm{OH}^{-}
$$$$
\mathrm{H}_{2} \mathrm{O} \rightleftharpoons \mathrm{H}^{+} \mathrm{OH}^{-}
$$$$
\mathrm{H}_{2} \mathrm{CO}_{3} \rightleftharpoons \mathrm{HCO}_{3}^{-}+\mathrm{H}^{+}
$$$$
\mathrm{HCO}_{3}^{-} \rightleftharpoons \mathrm{CO}_{3}^{-2}+\mathrm{H}^{+}
$$$$
\mathrm{Mn}^{+2}+\mathrm{HCO}_{3}^{-} \rightleftharpoons \mathrm{MnHCO}_{3}^{+}
$$

Log K

1

1.54

1.70

1.3

$-4.8$

$-10.6$

$-12.7$

$-14$

$-6.4$

$-10.3$

1.27 
